\title{
Effect of Name of Region on Tourism Image Slogan
}

\author{
Mingxiu Chen \\ College of Humanity \\ Northeast Normal University \\ Changchun, China
}

\author{
Mohan Zhu \\ College of Humanity \\ Northeast Normal University \\ Changchun, China
}

\begin{abstract}
With the tourism industry transition from resource-oriented to image-oriented, tourism image design is paid more and more attention. Close analysis on tourism image slogans of parts of cities in China shows the problems of similarity and formalization. As there is coherence between the name of region and the tourism image design in cultural connotation, uniqueness, chronicity, and so on, the name of the region should play a significant role in tourism image slogan and also be a key element.
\end{abstract}

Keywords—name of region; tourism image; image slogan

\section{INTRODUCTION}

As an emerging industry ,tourism due to its wide range of industrial linkage effects and multiplier effect, it had became a new growth point of regional economic development, many cities take the tourism industry as an important industry to develop. Today's tourism is buyer's market, there are many alternative choices for tourist destination, the tourists will compare with the images with the travel destinations and finally choose the one could meet their travel needs and psychological expectations. Tourism image has played a key role in determining the tourists' consuming behavior. Tourism image-building has attracted more attention to the local government, local government concerned tourism image planning and communication, actively develop in the design of area and the city's tourism image, main slogan and tourism representing system, open public solicitation activities for tourism image. Related scholars' research for tourism image was also in a climax stage. They have made tremendous achievements in the study of the basic theory of tourism image research. Tourism image design, local culture, and the market are basic foundation ; positioning is the core work for image planning and shape, which point out the direction of the image design; Slogan is the most common form of expression for tourism image; also will need the visual image symbol to design communication strategy and promote the tourism image (Wu Bihu, 2001).

However, the purpose of tourism image design is to enhance the awareness of the tourists to the tourist destination, increase the competitiveness of local tourism, and also promote local tourism development. So, what kind of image it should be able to really play the role of it? In addition to wellknown tourist image design has to content from the context, expression for the tourists, this article believes that the name of the region plays an important role in tourism image slogan, it is necessary to be considered as an important factor and reflected in the slogan of the tourism image.

\section{ClassifiCATION AND PROBLEMS FOR TOURISM IMAGE SLOGAN}

\section{A. Classification of Tourism Image Slogan}

Comprehensive analysis of the collected image of tourism slogans, they can be divided into 3 categories include: resource-oriented, idea-oriented and brand-oriented. When the same type of tourism resources in a region is more prominent compared to the surrounding area, or it is in the early stages of tourism development, only develop the most attractive resource, then they usually use the general resource-oriented slogan to reflect the characteristics of the region's resources ; when a regional tourism resources are not prominent or the resource is rich and varied and quite attractive, for a particular tourists source, in order to meet certain needs of tourists travel experience, they generally use idea-oriented slogan, use one or some idea word as the slogan to form its unique selling point, which is the most popular design for current domestic tourism image slogan; when tourist destination development is fullyfledged and it occupies an important position in the tourism market, city name itself was enough to bring to mind a certain type of tourism, you can use the brand-oriented slogan, which is to directly use the name of the city as the main content of slogan, such as the World Tourism Kingdom Spain, the tourism slogan is "Spain ,brand "China is now rarely seen such a slogan.

\section{B. Problems of Tourism Image Slogan}

Looking at the current domestic tourism image design, local tourism development of the city achieved by image promotion is very often, but when we compared the slogans from many cities, we found there are many problems about current urban tourism image slogan design. "Table I" 
TABLE I. TOURISM IMAGE SLOGANS FOR PART OF THE CITIES

\begin{tabular}{|c|c|}
\hline City & Tourism Slogan \\
\hline Dalian & "City of Romance", "Match in Beijing, Tourism in Da LIan" (Especially for Olympic.) \\
\hline Xiamen & "City of Warm and Sweet" \\
\hline Shanghai & "City of Fashion", "Shang Hai, Excellent everyday" \\
\hline Guangzhou & "City of Fine food” \\
\hline Nanjing & “City of Universal Love-World's No1 City Wall” \\
\hline Hong Kong & "Charming Hong Kong, city of All Things" \\
\hline Hangzhou & "Up above there is heaven, down below there is Suzhou and Hangzhou", "heaven on earth, happiness in Hangzhou", "City of Love" \\
\hline Suzhou & "Up above there is heaven, down below there is Suzhou and Hangzhou", "Eastern gardens, watery towns in Southern China" \\
\hline Yangzhou & "Going to Yangzhou in March" \\
\hline Zhuhai & "Cloud above the sea, Zhuhai under the sky", "City of Romance" \\
\hline Shenzhen & "New century city, window of China", "Shenzhen will bring you a new hope everyday" \\
\hline Xining & "Plateau summer tourism city" \\
\hline Changchun & "Spring city in North China, Site of Manchukuo" \\
\hline Jilin & "River city in North China, romantic tree and love ice" \\
\hline
\end{tabular}

1) The similarity for tourism image slogans: The similarity phenomenon of City tourism image slogan is very serious, especially in the idea-oriented tourism images, since the idea experience for a certain target tourist market has some degree of consistency, many cities in the tourism image design are not able to carefully analyze their own cultural history but directly grafting the image of others, causing the similarity without their own personality. "Pearl of the plateau" at least been used in 3 Western Highland tourist areas , "city of romantic" has become a sought-after signs, "Northern city" "Beyond the Great Wall" have been very common in the urban tourism image of related areas. Pearl and romantic both are beautiful words, but it does not reveal the difference between this "romantic" and another "romantic", this "Pearl" and another "Pearl" , today you use "romantic" and get success, tomorrow it will appears a "romantic city", then it will appears "romantic town", "romantic village"; they can not reveal the feature of "this one".

2) Tourism image slogan became "Jianghu slogan": For tourism image slogan, we like to use the accumulation of adjectives, or exaggerated for propaganda purposes, so that the image of tourism slogan becomes a "Jianghu slogan." Some places prefer fashionable rhetoric, trying to beautify its image, giving the impression of exaggeration, flashy and superficial, and it is commented as "excessive use of propaganda and ignore the real meaning." [1]. Tourism image can not be departing from the local context, find the best words to use on itself often will be considered as a joke. Today the environment has been more and more concerned, good urban environment especially good green has became a fashion. But a western city positions itself as "China Forest City" based on a tree belt surround the city. Regardless of the reason for the charge is insufficient, while the city environment among large cities is poor with no trees in town and it is called the "dust city". The tourists really can not get the where does this "forest City" come from on their own intuitive experience. In addition, the leading position as a preferred method of image positioning in the tourism image design plays an important role, however, leading needs to be established based on the local resource, there must be a real leading resources which is recognized by tourists, so leading will be able to be confident by its slogan so as to attract tourists. Do not be leaded, often use "world first", "Biggest", "Highest" etc. People do not understand where does this "first" come from and it will lead to a kind of resentment emotion.

\section{THE ACTION FOR ADMINISTRATIVE REGION NAME IN TOURISM IMAGE DESIGN}

Administrative division is the spatial projection of administrative system, it is the spatial arrangement of the national architecture and it is the local configuration of national interests. The Administrative Region is the result of the division, is the area under the jurisdiction of local administration of a country. Administrative Region is the platform for the ruling class in power and in economic development. Tourism as an emerging industry, its development is certainly no exception, needs to be based on the administrative platform. Meanwhile, the city's name often reflect the content of the integrated all aspects of its natural, economic, ethnic, historical, cultural, etc. It has a profound meaning with substantially unique nature and it is irreplaceable. Thus, the administrative name plays an important role in tourism image design.

\section{A. The Role of Cultural Connotation and Culture Context of Administrative Name in the Tourism Image Design}

Tourism image slogan design requirements the slogan must be derived from the substance of the uniqueness of the place so to avoid vague content. The so-called local culture context, 
refers to the city's geographic backgrounds include geology, topography, climate, soil, hydrology and other characteristics of the natural environment, also it include human geography characteristics such like local historical, social, economic and culture. Thus it is a four-dimensional space combination with comprehensive and regional natural geographical basis, historical and cultural traditions and social psychological accumulation [2]. Therefore, in order to reflect the unique personality of the city, we need to fully tap and analysis the context of the city, only regional difference is absolute and unlimited. The Administrative Region name include two elements: general and proper names, proper names mostly with their characteristics of natural geography, orientation and ethnic times, is the product of thousands of years of socioeconomic and administrative systems development [3]. Names of the city tend to comprehensively reflect the content of the various aspects of its natural, economic, ethnic, history and culture. Names came with the emergence of human society, and developed by following the pace of development of human society. It is not only played the role of refer on people's communication lives, but also reflects the development of economic, political and cultural in different era. So names are concentrated history and an abbreviation of culture, the relationship between Chinese place names and traditional culture can be described as lingering inseparable. Therefore, in the tourism image of the slogan can reflect the origin of place names, not only can directly tell visitors what destination you want to promote, also in a certain extent it can reflects local culture context. For example, the tourism image slogan for Tianjin is "former emperor's ferry crossing, now the Pearl of Bohai", Origin of the name "Tianjin" is because it is a ferry crossing from the land for the emperor in ancient, so that the slogan point the name of "Tianjin ", but also reflects the cultural connotation.

\section{B. The Uniqueness of Administrative Region Name and Specificity of Slogan}

The purpose to design tourism image is to be unique and stands out from many tourist destinations, therefore tourism image must have a specificity which is the vitality of the design. We must find out the difference between the tourism destination and other places even it is deliberately sought. Especially when they have similar resources and market, product substitution is strong, we must further explore the unique local culture, try to reflect the unique characteristics and avoid conflicts with competitors. When set up administrative region names, it requires the name to be as unique as possible in order to avoid confusion in management, especially in city name, rarely have the same name. Therefore, among the destinations with similar resources and approached regions, the name could reflect the difference in cultural and natural conditions to some extent. So when we design the destination tourism image, we have to seize the name. For instance, Fujian's tourism image slogan "A happy tour to a happy city", which fully captures the administrative region in the name of "Fu" , three fu words in the slogan, read fluently, to give a sense of good fortune, because of the uniqueness of place names and makes other destinations can not clone, it makes the image sufficiently specificity.

\section{The Permanence for Administrative Region Name and the Stability for Slogan}

Tourism destination image once formed, will produce the impression in the minds of tourists, in general, the impression of the image formed by the accumulation has relative stability. One reason is because the objective material basis of tourist destinations, such as resources, geographic location will not change in the short term; secondly, tourists have the same psychological mechanism, they all have the human nature of prefer the good things and hate the ugly things, especially the idea-oriented image based on the concept the tourists ' experience is more stable; and finally, one of the main function for tourism image is publicity, the image from the design to the media and then tourists cognitive accepted and widespread, it will take a long time. Thus, the tourism image should be stable. Administrative region names have experienced thousands of years of history in their formation process, the names are a comprehensive reflection of the natural and cultural status of local which is permanent. Therefore, reflect the Administrative region Names in image design is consistent with the image stability.

\section{CONCLUSION}

Administrative region name should be the foothold of the tourism image slogan. Cultural Connotations, uniqueness and permanent of the Administrative region Names are consistent with tourism image design requirements, so it should be the foothold of the tourism image slogan. Some of the world famous tourism places has a slogan contains their Administrative region Names, which achieved good publicity result and to a certain extent, promote the development of local and the country's tourism . For example: The USA California tourism image slogan is "The Californias", the slogan for the most famous tourism kingdom Spain has undergone changes in four stages, but each stage all contains "Spain" .Its four stages are "Spain, everything under the sun", "Spain - passion for life", "awesome Spain" and "Spanish brand"; its image of local tourism slogan, too, such as "Barcelona, brand "," Madrid, brand "and so on.

In addition, any tourist activities will ultimately be settled on top of the actual place where the image of tourism slogan is designed to be selected by the tourists. So the slogan should make the tourists understand where it advertised and where they can see the beautiful views or unique culture on the basis of adequately reflect the local resource conditions, promote the resource and the place at the same time. Slogan should include both the "what "and "where", form "where you can find what" a whole composed with two bodies, it can really complete the Slogan mission.

With the rapid development of tourism, the regional tourism competition continue to strengthen, tourism image has became a powerful weapon for Travel Destinations in market competition. Conscientiously study tourism image planning, provide the basis for tourist destination image design, and applied in practice to improve the image of local tourism competitiveness, promote local tourism development, it is of great significance meaning. 


\section{REFERENCES}

[1] Jin Yingruo Tourism destination image positioning and Requirements for Tourism Image Slogan Design [J]. Journal of Beijing International Studies University, 2003.1.

[2] Li Leilei. Urban Tourism Image Design [J]. Tourism Tribune, 1998.1

[3] Liu Junde Chinese Political geography [M]. Beijing: Science Press, 1999.

[4] Li Leilei Tourism Destination Image Planning: Theory and Practice [M] Guangdong Tourism Press, 1999.11.

[5] Wu Bihu Regional Tourism Planning Principle [M]. China Tourism Press, 2001.

[6] Miao Yajie Regional Tourism image Slogan types and influencing factors [J]. Tourism Forum, 2010.6. 